Geopolítica(s) Revista de estudios sobre espacio y poder ISSN: 2172-3958

https://dx.doi.org/10.5209/geop.78608

\title{
Pensar sin Estado
}

María Lois y Ahmet Akkaya (eds.) (2020) Estrategias descoloniales en comunidades sin Estado. Madrid: Los Libros de Catarata, 213 pp. ISBN: 978-84-1352060-5.

El Estado-nación aparece en la mayoría de los planteamientos académicos y políticos como un elemento inmutable, sólido, indispensable e inevitable. Nada habría más allá de los limites de acción de éste y sólo se tendría en cuenta lo que sucede en, con, por, para y contra el mismo. El proceso histórico de formación de los Estados-nación y el enmarcamiento de toda la vida sociopolítica a su existencia, se vería como un devenir lineal unidireccional. Agnew desarrolló toda la lógica que subyace a esta idea al hablar de "la trampa territorial". Aún así, en las últimas décadas desde la Geografía Política se habría ensanchado el objeto de estudio poniendo la vista en los procesos, en las comunidades políticas y en la relación entre espacio y poder más allá del Estado. El libro de Lois y Akkaya se adentra en este cambio de foco y viene a cuestionar este, supuestamente, inalterable planteamiento. Hay vida más allá del Estado e, incluso, la oposición al mismo se puede configurar desde planteamientos imaginativos, disruptivos, tradicionales y revolucionarios, que cuestionan, no sólo su necesidad, sino también las lógicas intrínsecas a su formación, devenir y funcionamiento como son el capitalismo, el patriarcado y la democracia liberal representativa. A través de distintos capítulos se nos plantea cómo distintas comunidades, pueblos y naciones sin Estado se relacionan con su propia situación de subalternidad, sus aspiraciones y sus prácticas contra y al margen de esta forma hegemónica de agrupación política surgida a finales del siglo XVIII.

La pregunta fundamental que nos plantea el libro se recoge de forma clara en su introducción, ¿es posible una nueva forma de organización fuera del encorsetamiento jurídico, territorial y político del Estado? (p.13). A partir de esta cuestión inicial, la obra recorre distintos escenarios planteándose los horizontes de posibilidad de las formas de autodeterminación política más allá del Estado. El devenir del pueblo kurdo en su lucha por su autogobierno y su autonomía democrática como posibilidad revolucionaria de ruptura a través de los capítulos de Ahmet H. Akkaya (pp.43-63) y Azize Aslan (pp.64-86); las posibilidades de resistencia del pueblo saharaui ante la pandemia de la COVID-19 fruto de sus propia experiencia de lucha

Ver J. Agnew: The territorial trap: the geographical assumptions of international relations theory. Review of International Political Economy, 1(1), 1994, 53-80. 
y organización política por su autodeterminación en el texto de Gimeno (pp.87106); las dinámicas de enfrentamiento diferenciado y construcción de identidad de la comunidad mapuche a raíz de sus distintas lógicas de relación con los Estados de Chile y Argentina como desarrollan Jerónimo Ríos, Mariano García de las Heras y Eduardo Sánchez (pp.107-132); la situación de resistencia, lucha y reconocimiento de las comunidades indígenas en México y Bolivia en los capítulos de Araceli Burguete (pp.133-153), por un lado, y Paola de la Rocha y Farit Rojas (pp.154-180), por otro; y, por último, la desigualdad y discriminación sanitaria de la primeras naciones en Canadá derivada del proceso de construcción estatal en su reparto competencial y sus lógicas asistenciales, como señalan las autoras Celia Luna y Vandna Sina (pp.181-209).

Como punto inicial de este compendio de análisis, Heriberto Cairo realiza una revisión de la formación de los Estados-nación para reflexionar sobre su carácter sociopolítico construido alejándolos de cualquier consideración que los visibilice como forma natural de organización política (p.28). El autor recorre distintos espacios y tiempos tomando como punto de partida la variedad de "pueblos" que han reflejado la diversidad humana agrupándose en tres tipos de concepciones: las razas, las naciones y los grupos étnicos (p.20). Tras una revisión de la acción humana en el espacio, el autor desarrolla la relación que se establece entre los Estadosnación, el territorio y la población, llegando a un planteamiento que contrapone territorialidad y reticularidad como tipos de gobierno/gobernanza en y más allá de las formas de organización política hegemónicas. De esta manera, parte en este análisis de la fórmula estatal-territorial para exponer las posibilidades que se abren, primero, desde el punto de vista de la descolonización, como forma de solución a diversas situaciones de subordinación dentro de los límites de acción y reacción del Estado-nación (p.29), y, segundo, desde planteamientos poscoloniales que han configurado un horizonte transformador donde la organización de la comunidad política va más allá de su articulación estatal apareciendo formas reticulares de gobernanza más allá del Estado (p.31).

A partir de esta revisión teórica, los análisis prácticos permiten conformar una realidad más tangible de las formas en las que estos planteamientos se asientan sobre el terreno. Las potencialidades de transformación y de ruptura con las formas estatales que ha configurado el pueblo kurdo abren la posibilidad a una propuesta de autoadministración local que no busca la imposición de una identidad dominante y cuya organización de la comunidad política se asienta en el confederalismo democrático propuesto por Abdullah Öcalan. El autor, Ahmet H. Akkaya, tras un repaso a las formaciones y organizaciones que el pueblo kurdo ha ido configurando a lo largo de su historia en su relación con los distintos Estados en los que se asienta, sintetiza la forma en la que la administración no estatal se ha planteado en Rojava. Más allá de la formación de un Estado propio o de una autonomía federal dentro de Irak como plantean el PDK y el PUK (p.51), en Siria, el PYD, plantea en su práctica teórica y política la necesidad de avanzar más allá de las reclamaciones de independencia y construcción Estatal. Se pasa a problematizar esta concepción y avanzar hacia formas de organización más disruptivas y transformadoras (p.54). El Estado no sólo acaparaba injustamente todas las aspiraciones de autodeterminación planteándose como meta a alcanzar, con el consiguiente desgaste político por su consecución no obtenida, sino que era un elemento generador de desigualdad en su 
relación con el modo de acumulación capitalista, la opresión patriarcal y el encorsetamiento jerárquico y autoritario en cuanto a la participación y a las posibilidades reales de transformación. Por lo tanto, la emancipación y autogobierno del pueblo kurdo pasa por ir más allá del Estado para vertebrar la comunidad política a través de la autonomía democrática y un autogobierno comunitario participativo. Por lo tanto, el confederalismo democrático "se trata de una forma de autoadministración, intrínsecamente autónoma. No parte de relaciones individualizadas y verticales entre los sujetos y un agente estatal, sino que plantea la cuestión de cómo deben relacionarse las personas entre sí" (p.61).

En este sentido se configura una libre determinación que vertebra una autonomía y una autodeterminación no estatal y "desde abajo" como formas de decisión sobre la vida individual y colectiva, como expone Azize Aslan (p.66). Esta autora profundiza en la idea de cómo esta no estatalidad también es disruptiva con los procesos económicos, sociales y políticos asociados a la misma, por lo que se articula como anticapitalista, antipatriarcal y radicalmente democrática. Por lo cual, la ruptura y la transformación se complementan con la profundización democrática, la liberalización individual y colectiva y, como ruptura con el sistema de dominación de género y el orden social establecido, con la autorganización de las mujeres (p.80).

Este ejemplo nos muestra las posibilidades de ruptura con la sempiterna lucha por la consecución de la forma estatal, pero, aportando otra lógica, el capítulo de Gimeno nos presenta cómo se consolidan formas de organización y autogobierno de facto de comunidades políticas en un camino hacia la autodeterminación dilatado en el tiempo. El pueblo saharaui, en la espera de alcanzar su independencia por un proceso de descolonización sin resolver en la actualidad frente a España y Marruecos, ha configurado una comunidad política articulada en una administración de base estatal sin reconocimiento internacional (República Árabe Saharaui Democrática). Manteniendo, de forma paralela, una gran cantidad de población viviendo en zonas bajo ocupación marroquí o en el exilio (p.90). Por lo tanto, la aspiración se centraría en la conformación de un Estado-nación clásico, pero en ese impasse se habría configurado una lógica de autogobierno efectiva aún sin Estado. La situación de confinamiento y aislamiento impuesto habría generado lógicas de autogobierno atravesadas por prácticas culturales y de organización colectiva derivadas de la tradición nómada, por cadenas de cuidados, donde las mujeres saharauis tendrían un papel fundamental, y por una unidad de acción producto de décadas de lucha anticolonial, que habrían permitido una cierta respuesta efectiva ante la pandemia de la COVID-19 en los territorios liberados bajo administración de la RASD (p.96).

Avanzar en esta reflexión sobre la articulación de las comunidades políticas más allá de la lógica estatal también supone poner el foco sobre la existencia de aquellas que son preexistentes a la configuración del Estado-nación moderno y que, por lo tanto, aparecen sumidas en una lógica de represión-resistencia, aislamientointegración y reconocimiento-asimilación. La creación de los Estados-nación de Chile y Argentina, posterior a la ancestralidad mapuche, habría sometido a este pueblo a una doble presión. Por un lado, la lógica centralizadora y homogeneizadora del proceso de construcción estatal y, por otro lado, el proceso de acumulación capitalista articulado a través de la presencia de multinacionales en su territorio 
(p.114). Por lo tanto, la aparición de los dos estados habría quebrado la integridad y cohesión territorial de la identidad mapuche provocando una reconfiguración, diferente a cada lado de la frontera, de esta identidad, que se vería sometida a lógicas económicas y estatales diferenciadas provocando formas distintas de resistencia, integración, negociación y reconocimiento.

Estas comunidades también desarrollan ciclos de movilización, repliegue y de reconfiguración de sus relaciones con el Estado. Así, la autora Araceli Burguete nos presenta cuáles han sido los ciclos de movilización y reformulación del Congreso Nacional Indígena en México pasando por la confrontación, la negociación y, por último, una doble vertiente con la aparición de un autogobierno de facto con las Juntas de Buen Gobierno, por un lado, y un intento de candidatura electoral, por otro. De esta manera, la acción de estas comunidades políticas ancestrales ha encarnado diversas vías de relación con la estatalidad. Desde la confrontación directa en términos de enfrentamiento armado, para después iniciar un camino de negociación en búsqueda de reconocimiento y autonomía por parte del Estado, hasta finalmente dar por superada las fronteras de la acción política en, contra y con el Estado creando una nueva forma de organización político-territorial autogobernada desde la que repensar su devenir.

Siguiendo en este ámbito, la relación con la estatalidad de estas comunidades puede llevar a la paradoja por la cual un Estado construido posteriormente a las mismas tiene que reconocer su existencia previa por vía de mecanismos administrativos que legitiman su autonomía en base a adecuarse a lógicas de reconocimiento de lo que es "ancestral" en términos del propio Estado. Así, como exponen Paola de la Rocha y Farit Rojas para el caso de lo indígena-originario-campesino en Bolivia, se reconoce una existencia ancestral previa a la forma estatal la cual debe asimilarse a la concepción de ancestralidad construida posteriormente, Estado mediante, para ser reconocida como previa y dotarla de autonomía. Esto hace que esos pueblos indígenas se adapten, modifiquen y creen estructuras distintas a sus prácticas ancestrales para poder pasar el filtro de la ancestralidad y el reconocimiento "nos coloca delante la necesidad que tienen los pueblos indígenas de actuar, de poner algo en escena, de generar una performance, una actuación para los no indígenas que les permita ser tan indígenas como ellos esperan" (p.167).

Así, el Estado termina teniendo una preeminencia jerárquica sobre algo que en principio reconoce como previo a su propia existencia. Esta preeminencia puede partir de un reconocimiento de autonomía dentro de un Estado plurinacional como sucede en el caso boliviano, pero también de un Estado que mantiene una lógica colonial que, pese a establecer un reconocimiento legal, somete a desigualdades estructurales en el acceso a servicios a estas comunidades políticas que son formalmente reconocidas, pero a las que se somete a una situación de exclusión real. Esto sucede en el caso de las Primeras Naciones en Canadá que ven privado su acceso a una asistencia sanitaria en los mismos términos que el resto de ciudadanos como recogen Celia Luna Vives y Vandna Sinha. Pese al reconocimiento legal formal, la estructura colonial que se mantiene en la construcción estatal prolonga esta situación de subalternidad en base a tres factores: falta de financiación, actitud paternalista por parte del Estado y aislamiento geográfico. Por lo tanto, los límites estatales van más allá del reconocimiento formal y mantienen una jerarquía y exclusión en base a la existencia de comunidades políticas privilegiadas, las integra- 
das en la idea tradicional del Estado-nación, y comunidades políticas excluidas, las que se salen de esa lógica por su existencia previa o por no asimilarse a la construcción nacional.

En todos los casos analizados a lo largo de la obra la idea de los límites de la forma Estado aparecen dibujados con distintos contornos. Como reflejos de un tiempo pasado de reclamación superados por nuevas formas de organización política transformadora; como expresiones de formas de negociación y confrontación para alcanzar un estatus estatal o de autogobierno dentro o fuera de sus contornos; o como estrategias de reconocimiento de distintos niveles o situaciones de inclusión/exclusión en términos de comunidades políticas preexistentes. El Estado aparece a veces como anhelo, otras veces como represor, en algunos casos como interlocutor $\mathrm{y}$, en la práctica política diaria, como forma de organización y gestión superada o con posibilidades de superación. Por lo tanto, la realidad demuestra que se puede pensar más allá de sus esquemas y límites aspirando a vivir a contracorriente.

Sergio Claudio González García Departamento de Historia, Teorías y Geografía Políticas Facultad de Ciencias Políticas y Sociología Universidad Complutense de Madrid Email: segonz01@ucm.es 